Thursday, September 29, 2016

09:45 AM - 10:00 AM

P Convention Center - Room W232 B

Introduction: Stomoxys calcitrans (stable fly) has historically been a pest of dairy cattle and feedlots due to the availability of decaying plant matter mixed with animal excrements in such production systems. In the last few decades, S. calcitrans outbreaks have also been reported in different situations. Population explosions of $S$. calcitrans flies may also have natural causes, affecting not only domestic and/or wild animals but also humans.

Methods: Field investigations

Results/Conclusion: In Brazil, annual losses directly caused by this fly may reach up to US\$335 million, excluding the impact caused by recent outbreaks reported in distinct regions of Brazil. Outbreaks have generally been concentrated in the Mid-west and Southeast regions of the country, reaching five different states. Sugarcane and alcohol production wastes, particularly sugarcane filter cake and mulch mixed with vinasse, are the most suitable substrates for the development of stable fly larvae. A close relationship has been observed between sugarcane mill wastes and mass production of $S$. calcitrans. The lack of appropriate management methods for preventing the development of $S$. calcitrans in sugarcane mills, as well as the lack of sanitary management in livestock facilities, has contributed significantly to the multiplication of larval habitats in these areas. Several recommendations have been put forward to prevent and control stable flies at sugarcane mills and cattle ranches, mostly involving environmental management practices aiming to eliminate developmental sites. Only coordinated and integrated actions will effectively reduce both frequency and intensity of stable fly outbreaks until effective solutions can be devised.

doi: 10.1603/ICE.2016.108897

\title{
Authors
}

Paulo Cancado

Embrapa Beef Cattle

\section{Thadeu Barros}

Embrapa Beef Cattle

Taciany Ferreira Dominghetti

Federal University of Matogrosso do Sul

Cleber Soares

Embrapa Beef Cattle

\section{View Related Events}

Symposium: 467 Symposium: Stable Flies in Agroecosystems: An International Problem

Program: Symposium

Day: Thursday, September 29, 2016 